\title{
LA SOCIOFOTOGRAFÍA. Aportes epistémicos para una triangulación entre fotografía y antropología
}

\author{
Juan Erick CARRERA ARENAS \\ Universidad Católica de Temuco (Chile) \\ jcarrera2014@alu.uct.cl,patriciocarrera.a@gmail.com
}

\begin{abstract}
THE SOCIAL PHOTOGRAPHY. Epistemic contributions for a triangulation between
\end{abstract} photography and anthropology

Resumen: El estudio de la condición humana indubitablemente requiere del máximo de recursos disponibles. En este caso, la fotografía constituye, en sí misma, un potencial sistema de representación y materialización de los fenómenos sociales. No obstante, lograr su inclusión en las metodologías, especialmente socioantropológicas, es un trabajo que requiere mucha dedicación. Es por ello, que pensar en una sociofotografía como área de estudio investigativo, es pensar en ciencia, filosofía y arte, como fundamentos concretos de la existencia humana. Es la intención de generar un diálogo teorético que nos conduzca al terreno empírico donde la realidad de los fenómenos sociales es igualmente interpretada y no solo objetivada. Para así, contribuir a un verdadero holismo en las disciplinas que explican, traducen o interpretan la realidad social.

Abstract: The study of the human condition, indubitably needs of the maximum available resources. In this case, the photography constitutes, in if same, a potential system of representation of the social phenomena. Nevertheless, to reach his incorporation in the methodologies, especially sociological and anthropological, this is a work that requires a lot of dedication. It is for this, that to think about a social photography as area of research study, is to think about science, philosophy and art, as concrete thoughts of human existence. This is the intention of generating a theoretical dialogue, that we leads us to the empirical area, where the reality of the social phenomena equally are interpreted and not only objectified. For of this form, to contribute to real holism in the disciplines that they explain, they translate and they interpret the social reality.

Palabras clave: Fotografía. Investigación social. Representación social. Interpretación. Antropología social Photography. Social research. Social representation. Interpretation. Social anthropology 


\section{Introducción}

Este articulo está orientado a entregar, con una particular perspectiva, los conocimientos necesarios para poder comprender qué es la sociofotografía, cuáles son sus límites y posibilidades, cuál es su orientación metodológica, y lo más impetuoso, cuál es su valor en una sociedad donde la superficialidad carcome lentamente la construcción de un conocimiento, si quiere decirse, mas cientificista sobre esta disciplina, y con ello, la naturaleza de su impacto en una sociedad movediza.

A través de este texto, pondremos nuestra atención sobre elementos que construyen esta mimesis sensacional-experiencial de la realidad, entendida desde su amplio espectro conceptual. Elementos como el imaginario social, la interpretación colectiva, la racionalidad espontánea, el discurso, la significación y las formas simbólicas son, entre otros, los orientadores que nos entregan las huellas para poder estudiar lo que debemos comprender como un hipertexto; poli-comprensivo, poli-interpretativo y poli-significacional; la fotografía.

Así, comprenderemos lo complejo de estudiar al (los) sujeto (s) mismo (s), desde un enfoque socio-antropológico, sociosemiótico y filosófico, entendiendo que la relevancia de la fotografía nace justamente en la representación social, en los procesos discursivos, en la historia y en el valor que merece un documento moderno invaluable en el estudio de la realidad y las sociedades culturales.

\section{La sociofotografía}

Hablar de fotografía es algo naturalmente confuso, más aún cuando se trata de la asimilación y construcción de un texto de orientación teórica, pues la apuesta que aquí se manifiesta inunda nuestras percepciones epistemológicas sobre cómo podríamos contribuir a una teoría de la sociofotografía.

Por otro lado, la sociofotografía, se transformaría en una disciplina que estudia un complejo sistema de construcción, representación e interpretación de la realidad, a través de la praxis y análisis sociofotográfico, lo cual es necesariamente abordable desde una multiplicidad de disciplinas y perspectivas teórico-metodológicas, como lo son; la semiótica, la hermenéutica, la estética, entre otras. En general, la palabra la tiene la ciencia y la filosofía, en este caso, atribuidas a una socioantropología.

Puede parecer temerario intentar adjudicar estos conceptos a lo que comúnmente se considera un arte, sin embargo, cuando repensamos la ciencia, o bien, el cientificismo sociológico, en este caso, no aludimos a una eterna yuxtaposición humanista, pues la fotografía social en sí misma es humanista, pero para llegar más allá de los planteamientos reflexivos evidentemente adjudicables a la crítica y el sentido común, es menester reestructurar los conceptos que de alguna manera nos permitan posicionar a la fotografía, considerando su matriz social, visual y linguiística, en un estado de exploración académica que permita su utilización en la investigación social, o en general, en las manifestaciones que confluyen en el estudio de la condición humana.

Así, la fotografía puede ser hoy muchas cosas, desde un arte visual-gráfico, una estructura de lenguaje, un sistema de representación de la realidad, una respuesta a la organización semántico-discursiva, o bien, como lo manifestara Pierre Bourdieu (2003), un arte intermedio. En efecto, dada la complejidad de catalogar, lo que es una disciplina con elementos de física y química (en la análoga), de diseño gráfico (en la digital), o de óptica geométrica (en su maquinaria), y que tras un complemento de percepción e interpretación, constituye un complemento entre un mecanismo teórico-metodológico y elementos técnico-pragmáticos que en un proceso-relacional tiene como resultado lo que ingenuamente creemos conocer como fotografía. No obstante, comprenderemos en este trabajo una diferencia contundente 
entre la fotografía como objeto material, y la sociofotografía como disciplina que estudia lo social a través del objeto (material) fotográfico.

Ahora bien, esta socio-fotografía, que en otros términos podemos denominar tradicionalmente (en parte) como la fotografía documental, y (algunas veces) el fotoperiodismo, es el resultado de la unión de bloques indisolubles, elementos técnicos, teóricos y sociológicos, que no necesariamente (como podemos creer) son de sentido común, que en esta unión nos entregan algo más intenso que la propia imagen, es cómo se reconstruye socio-imaginariamente esa imagen, es por ello que esta disciplina es necesariamente abordable desde la interpretación y el análisis sociosemiótico, eso le otorga una cualidad y complejidad característica; la interpretación de la interpretación. Esto lamentablemente ha resultado en la omisión de esta en el mundo académico e intelectual de las ciencias sociales, concediéndole un grado de inferioridad o superficialidad que, a mi parecer, solo es una reverberación de una indiferencia compuesta por dos ingredientes fundamentales; el metodologismo canónico y el tradicionalismo académico.

Entonces, para poder comprender y explicar la fotografía, para acceder a sus posibilidades, antes que todo, debemos aproximarnos a ciertos paradigmas teóricos necesarios, para así, vislumbrar que la fotografía no es como mal se entiende un hobby banal, o más pesimistamente, un instrumento de objetivación social, sino, que es todo un proceso de construcción y manifestación sociocultural, pues tras ella se esconde la historia, la realidad desde las más naturales percepciones, desde las manifestaciones propias del imaginario y la institución social, y desde las diferencias propias de la intersubjetividad y la descontextualidad interpretativa. Es por ello, que el objeto fotográfico es una herramienta perfecta para el estudio socio-antropológico pues, nos permite interiorizarnos en el pensamiento y repensarlo, nos permite ver a la sociedad desde adentro y desde afuera, y además, dejamos el sesgo de conceptos como "etnofotografía" o algún sucedáneo propio de la condición posmoderna a un lado, construyendo un todo disciplinario, mas cientificista y riguroso.

El análisis fotográfico, debe construirse de acuerdo a un sistema (o método) de desestructuración, para esto, y considerando lo anteriormente expuesto, podemos acercarnos a la escuela estructuralista-semiótica, con representantes como Lèvi-Strauss, Barthes, Jackobson, Derrida, Foucault, etc. No obstante, transformar el todo en partes, como estudio sistémico social, sugiere en cierto modo que a través de la fotografía podemos vislumbrar la estructura social (fundamento del estructuralismo). Y por otro lado, comprenderemos que la comprensión es el aspecto hermenéutico trascendental de la condición humana, que de igual forma, sustenta la representación imaginaria de la fotografía como reflejo de la realidad, en tanto es una construcción del sujeto. Para ello, podemos acercarnos a la escuela hermenéutica de Gadamer, Ricoeur, Dilthey, Heidegger, etc.

Al comprender que la desestructuración fotográfica nos revelaría una cantidad considerable de signos; icónicos, índices, iconográficos, semánticos, discursivos, etcétera, que en definitiva para un espectador o spectator (Barthes, 2008) codificarán las unidades de significado cultural que posteriormente serán significantes, y más allá, significados, es necesaria la comprensión del contexto de producción. Naturalmente, siempre existirá un sesgo en la interpretación, cualquiera sea la índole, desde la interpretación de la imagen, hasta la interpretación de los fenómenos sociales, del "acontecimiento", y por qué no matizarlo ontológicamente, de la vida misma. Pero el relativismo de la fotografía no la hace menos potencial en la investigación, al contrario, solo nos abre los pasadizos de las posibilidades, en un principio hermenéutico que necesariamente debemos considerar en el estudio de lo social, considerando que este relativismo, no es sino, una manifestación social.

Asimismo, en el mundo de la investigación antropológica existe la tendencia histórica de alejar los elementos ordinarios-cotidianos en la búsqueda de la extrañeza, esto considerando las clásicas metodologías aplicadas, pero sin embargo, en la fotografía es justamente lo que buscamos, aquel signo que procesamos y transformamos en relevante, es la belleza 
y la tragedia del punctum barthesiano, que interiorizándolo con nuestra percepción y predisposición analítica, construye lo fascinante de la fotografía, la hace pensativa, y en consecuencia, susceptible de analizar al otorgarle un sentido. Lo interesante, es que esa acción fenoménica (punctum), no se encuentra más allá de lo que es naturalmente, o real, por lo tanto, la relevancia está justamente en la búsqueda del sentido tanto elemento fundamental de la realidad social.

Entonces, más allá de una excusa superflua que motiva los debates sobre si la fotografía es arte o no (que en parte lo es), que por lo demás, se fundamenta en una negación obtusa fundamentada por el desconocimiento y la indiferencia, debemos intentar introducirnos en la complejidad de los mundos sociales, pues la significación de la fotografía radica precisamente en aquellas huellas que podamos encontrar en nuestra búsqueda, tanto como elemento de investigación sociocultural, o como manifestación de la memoria social. Así, todas las expresiones que se ocultan tras los signos fotográficos, conforman una construcción histórica en todos sus espectros sociales, desde la historia de una sociedad, hasta la de una unidad familiar doméstica. Por ende, el énfasis que le otorguemos dependerá eventualmente del tipo corpus fotográfico y de la orientación de la investigación.

\section{El origo fotográfico}

El objeto fotográfico tiene un telos original, este se ve definido en la experiencia del fotógrafo, aquella finalidad puede suscitarse de manera consciente o subconsciente. O sea, la idea de transmitir un hecho, un fragmento de realidad, puede ser construida intencional odícese - fortuitamente. Pues bien, en la construcción fotográfica no existe lo fortuito. Desde la sociología, Pierre Bourdieu (2008) habla del sentido de familiaridad, que en esencia es lo que nos impide encontrar significaciones en las acciones sociales limitadas a nuestro campo cognoscitivo. Probablemente, consecuencia del habitus. Pues, aquí hablaremos del sentido de contrafamiliaridad, el cual podemos definir como una versión antitética de nuestras experiencias, que asimiladas por nuestro subconsciente conducen al fotógrafo a buscar "recordarlas" o quizá imaginarlas, esto a través del spectrum original. Probablemente, también producto del habitus, tanto este influye en la sintaxis de la imaginación. De esta forma, podemos proponer que la fotografía social es el resultado de dos actos de conciencia; Por un lado, la experiencia sensible, que es la que podemos percibir cotidianamente, donde nace nuestro conocimiento de la realidad y por tanto aprehendemos y construimos nuestra historia. La experiencia sensible, es la consecuencia de todo nuestro proceso de construcción de identidad subconsciente, pues la aprehensión del contexto sociocultural, la adquisición de una lengua vernácula, el conocimiento cotidiano, en el fondo, todas aquellas manifestaciones socio-identitarias que se manifiestan de manera cotidiana, y que ponemos en práctica a diario (conciencia práctica) son producto de la experiencia sensible.Y por otro lado, tenemos la experiencia ontológica. Es aquí donde asumimos el conocimiento de lo real a través de la interpretación de una existencia dada, los hechos, los entes, el Ser, solo existen porqué están ahí, sin embargo, eso no significa que los comprendamos, o que conozcamos su funcionamiento, su finalidad o su origen, mas complejamente, su naturaleza. Es por ello, que este nivel de realidad es opuesto a un epistemológico ${ }^{1}$. Asimismo, esa incomprensión de la realidad es la que produce el sentido de contrafamiliaridad, sin embargo, esto no quiere decir que signifique una antítesis del conocimiento de un hecho mismo, sino que es la antítesis de la comprensión propiamente social, es decir, el conocimiento consciente, más cercano a un conocimiento intuitivo.

Ahora bien, este conjunto sígnico estructural, (independiente de su representación) al

1 No se aplica el concepto epistemológico en su cercanía al conocimiento científico, sino que al conocimiento del sujeto y su vínculo con lo social. Asimismo, no aplicaré la Gnoseología en este caso por la amplitud de su significación. 
que denominamos spectrum, es el resultado de una de estas dos proposiciones conceptuales, asumiendo la relatividad de esta idea. No obstante, habrá que explicar más detalladamente cómo se desarrollan en la conciencia de los intérpretes-interpretantes (operator y spectator). En efecto, podríamos tan solo considerar un emisor y un receptor, sin embargo, el operator se transforma en receptor antes que emisor, por lo tanto, existe una realidad que se omite o que cambia en la fotografía, una transrealidad que divaga de interpretación en interpretación tras el acto semiósico. Esta transmutación de la realidad que se experimenta a través de la percepción del fotógrafo, y posteriormente de los interpretantes, solo se conserva en términos estético-físico (composición), pero no se comprende en absoluto sin su contexto original, el cual otorgaría un sentido denotativo a la imagen. En parte, este fenómeno constituye una muerte de la realidad, o por lo menos de una parte de ella, en un efecto que se disocia de nosotros (como fotógrafo o espectador) inmediatamente al ser "memorizada" por el objetivo lenticular, esto debido a que al constituirse empíricamente la imagen (a través de la praxis del operator), deja de ser lo que era, pero sigue existiendo de una manera ontológica, sin embargo, su significación primaria y contextual se transforma en la construcción de múltiples interpretaciones de realidad. Por un lado, el argumento subjetivo del fotógrafo, y por otro, el imaginario social en el cual está subsumida la interpretación del espectador. Entonces, es por ello que no hablamos simplemente de la muerte de una realidad, sino que este fenómeno es una transmutación de la misma, hablamos de percepciones, porque ésta puede existir y no existir a la vez de una manera conceptual-dimensional, una transrealidad que está en constante resignificación.

Entonces, de manera de organizar esta idea, comprenderemos que hablamos de la relación conciencia-realidad y la interpretación como consecuencia de un proceso imaginario colectivo. Por un lado, la fotografía "es" de acuerdo a la dimensión de realidad, y por otro, su significado es el reflejo del contexto donde situamos a los sujetos interpretantes.

\section{La significación fotográfica}

La significación fotográfica nace desde una dimensión consciente, del mundo de las reflexiones y de la realidad epistemológica, que a través de las interpretaciones le otorgan sentido a las cosas, en este caso, al hipertexto fotográfico. Entonces, es menester señalar que no existen sentidos individuales en los procesos semiósicos de los sujetos, esto desde una apreciación externa, pues los "individuos" grupales mantienen una carga imaginaria valórica, ética, moral, política, lingüística, mitológica, folclórica, etc., que indudablemente influye, o más bien, son el génesis de sus significaciones a posteriori. Vale decir, toda representación e interpretación del mundo, nace desde una condición de existencia dada, por cuanto los sujetos existen (conscientemente) en tanto sus referencias lo han influenciado en una determinada sociedad y le han otorgado una identidad, (por ejemplo, el etno/nacionalismo como imaginario instituido), en este caso, la imagen fotográfica representa un discurso de la identidad social construida mediante la recepción subconsciente de las formas simbólicas, o las formas a priori ${ }^{2}$, lo cual es a su vez, es constituyente de la comunicación socio-visual, bosquejando el pasado, presente y devenir social

Por lo tanto, es claro que las percepciones tienen un anclaje cultural histórico y situado, que en un determinismo imaginario categoriza a los individuos y los hace sentirse pertenecientes a determinados contextos, y en consecuencia, toda interpretación estará reflejada en estas categorías sociales, en su propia percepción de la realidad, lo que nos manifiesta que la interpretación de la fotografía no podría ser ad libitum. Entonces, la fotografía se transforma en un referente empírico de nuestras percepciones, pues su sentido está condicionado por nuestra historia, por nuestra visión de mundo y por nuestras experiencias, de este modo,

2 Kant, en Crítica de la Razón Pura (2002), define las formas a priori como la síntesis de las sensaciones experienciales. 
capturamos nuestros significantes y lo revelamos a través del significado, es decir, el significado que podamos construir mediante el uso consciente y subconsciente del lenguaje (el portador de nuestra historia y realidad) no es más que una reverberación de nuestro contexto, con una entusiasta, pero ilusoria apariencia de autenticidad.

Desde un punto de vista estructuralista, ya lo había manifestado Foucault (1997), con su célebre y algo nietzscheana frase el hombre ha muerto. En efecto, que significa esto, cuando Descartes (2007) pone al sujeto en el centro de una totalidad a través del Ego cógito ergo sun (yo pienso, luego existo) con una excepcional prioridad racional, donde el hombre era sujeto constituyente de la historia, y con esa premisa se lanza a la conquista de los entes, Foucault, al "matar" al hombre lo que está haciendo, es decir que el hombre ya no es constituyente de la historia, sino constituido por la sociedad, por un sistema de poder estructural. Asimismo, la magnitud de los sentidos y las interpretaciones condenan a las ciencias sociales a estudiar los hechos sociales (en un sentido durkheimniano), a cosificar la realidad, centrándose en la observación de lo limitadamente distinguible. Sin embargo, Nietzsche ya interpretaba que no hay hechos, solo hay interpretaciones de hechos, y pues Foucault, supo nutrirse muy bien de esta tesis.

Por otro lado, en la fotografía, o más bien, en la sintaxis fotográfica, sucede algo muy similar a lo que Leví-Strauss (1987) entiende por estructura. Pues bien, si las partes (en relación) de un sistema determinan el todo, y la modificación de una o más partes, conllevan la modificación de la estructura, en la fotografía esas partes son significaciones, el objeto fotográfico sería el equivalente a un extracto del modelo de estructura, que se define transmutable de acuerdo a las variables significacionales de determinados contextos sociales. En otras palabras, la estructura de la imagen fotográfica, por cierto no observable, es definida por las significaciones que cada contexto le otorgue, donde es evidente la incidencia del imaginario instituido y todos aquellos elementos que intervienen en la construcción de la realidad social, la conciencia práctica y el conocimiento situado en las constantes interacciones experienciales.

Ahora bien, intentar estudiar las interpretaciones sociales a través de la fotografía no es tarea simple, pues conlleva la complejidad de interpretar las interpretaciones. Por lo tanto, comprenderemos los pasos errantes de la verdad absoluta en esta cuestión, y al decir anteriormente que no existen hechos, sino interpretaciones de hechos, desde un prisma hermenéutico, estamos comprendiendo que tampoco existe una verdad absoluta, más allá del alejandrinismo científico. Esto puede sonar conflictivo racionalmente, empero, la "verdad", que en este caso, está constituida por la realidad, por las experiencias e interpretaciones colectivas, no es más que una respuesta automatizada de representación de la realidad, que en efecto, podemos llamar "verdad objetiva", o mejor aún, "objetivación de la certeza". En definitiva, la verdad, o bien, un absoluto, siempre será sociológico, pero en ningún caso, ontológico. Al igual que la interpretación sociofotográfica.

Entonces, llegamos a esto que nosotros llamamos "realidad", que se manifiesta en el spectrum de la fotografía social, y que es lisa y llanamente nuestra percepción del mundo, tal y como nos la han enseñado a través de la enculturación y los niveles de aprendizaje (consciente/inconsciente), y todo lo que ello implica; la creencia del bien y el mal, la ética, estética, religión, moral, ciencia, la magnitud colosal de las mitologías, el discurso como sistema de representación, etc., en general, es el resultado de la experiencia en interacción con las formas simbólicas, entendiendo estas formas como un sello distintivo de las sociedades culturales, que a través de las sensaciones y experiencias de/re/construyen la realidad (Cassirer \& Imaz, 1963). Asimismo, la interpretación es consecuencia de la experiencia y eso la hace inauténtica (en términos heideggerianos), contextual, e incluso colectiva y homogénea. De este modo, la interpretación fotográfica está condicionada por los significantes, estos signos que deambulan de una conciencia a otra, transportando signos abstractos poli-interpretables, como por ejemplo la percepción de pobreza, de soledad, lo cotidiano y 
su distinción contextual, que se traspasan de emisores a receptores, en este caso, desde el fotógrafo u operator a spectator o espectador (en terminología Barthesiana).

El spectrum de la fotografía, constituye el transporte de los signos que en definitiva serán interpretados. Este spectrum no es la fotografía en sí misma, sino, su estructura conceptual, es decir, la conformación "fantasmagórica" de ciertas realidades, cuyo sentido (para Barthes) es transportar la muerte de una manera, en cierto punto, espectacular (haciendo caso a la etimología del término). Sin embargo, aquí dejaremos algo de lado esta interpretación esencialista cercana a un Tánatos freudiano, pero brillante en su lógica existencial, y en este relato nos referiremos al spectrum como un sistema de signos modificables que vagan contextualmente y asumen una "verdad" relativa (interpretación) de acuerdo a cada realidad. Pues será aquella transmutación la que construya el sentido de la imagen, por lo que el spectrum, conforma algo similar al modelo estructuralista.

\section{La racionalidad espontánea}

El sujeto hermenéutico, es sujeto susceptible de adquirir capacidad interpretativa (Foucault, 2002), y la interpretación tiene diferentes dimensiones. Sin embargo, existe un proceso interpretativo que se relaciona a la experiencia sensible. No obstante, cabe señalar que las prácticas de sentido común no necesariamente corresponden a fenómenos no racionalizados, pues el sentido es un atractivo sistema de adquisición de realidades, sean estas construidas por un propio contexto de incidencia epistémica, u otro ajeno. Entonces, la racionalidad espontánea como la propongo acá, es un proceso que se sustenta por aquel primer "conocimiento" que tengamos de alguna realidad, donde nuestra interpretación se relaciona de manera consciente e inconsciente, y a través de estos elementos significamos las experiencias.

En el caso de la interpretación fotográfica, es indudable la manifestación de una racionalidad espontánea, la cual construye categorías de realidad asociadas indiscutiblemente al contexto del sujeto interpretante, donde los códigos lingüísticos son significados en una semiosis situada y limitada por nuestro conocimiento histórico y nuestra carga semántica (experiencial-sociocultural), donde confluyen ideas valóricas, políticas, morales, sociales, etc. En resumidas cuentas, la fotografía jamás será interpretada de la misma forma en diferentes contextos, y aunque creamos tener comprensión de ciertas realidades, no significa que la comprendamos realmente, pues la racionalidad espontánea es un espectro cognoscitivo que nos hace "conocedores" de lo desconocido.

Para explicarlo de otra manera, la racionalidad espontánea es un proceso cognoscitivo mediante el cual el sujeto interpretante, o spectator, sugiere tener consciencia de cierto significado, sin embargo, este significado, que es sustentado por ciertas categorías significantes no constituyen más que una construcción significacional pre-instaurada en su imaginario (imaginario colectivo), más lo único individual, o de mejor manera, originario, es el emisor, que en este caso, intenta distinguirse del resto con elementos sub-culturales arrastrados por su imaginación en interacción con el contexto de producción. Una transmutación de representaciones de realidad, lo heterogéneo de la transrealidad.

\section{De la interpretación al estudio socioantropológico}

De esta manera, debemos analizar cómo es posible una triangulación entre la fotografía social y la investigación socioantropológica, donde claramente las posibilidades de estudiar la fotografía social desde las ciencias sociales se suscitan tras la comprensión de un habitus socio-imaginario como proceso interpretativo. Esto significa que, en definitiva, es el resultado del proceso de producción fotográfica el que se encuentra en nuestras manos, no así, la complejidad ontológica y metacognitiva del acto individual en la creación de la fotografía. 
Consciente estamos de que los estudios de la interpretación se apoyan fundacionalmente en los procesos de comprensión (Schleiermacher, Dilthey, Betti, Gadamer), pero cuando hablamos de estudiar sociológicamente la interpretación, es necesario abordar aquellos principios teóricos en busca de aquello, que más allá de lo ya tradicionalmente interpretado, nos conduzca a una base teórica sólida en el ambicioso estudio de las interpretaciones sociales. Desde esta perspectiva, en necesario poner en cuestión aquello que analizamos como una interpretación, su origen, su genuinidad, o su realismo. Así, podemos entender el fenómeno del simulacro planteado por Baudrillard (1998), lo que asociamos necesariamente a lo que llamábamos racionalidad espontánea, entendiendo la ambigüedad natural de la realidad y la razón. Pues más allá de los planteamientos hegelianos que afirman que la realidad es realidad en tanto razonada, y viceversa, el simulacro, conforma una realidad por cuanto es ejecutora de verdades. Estas verdades colectivas, producto del imaginario instituido, no son otra cosa que el resultado del discurso en interacción con los sentidos de los sujetos. ¿Acaso esto significa que siendo una construcción fantasmagórica discursiva, la esencia del simulacro de realidad no la constituye como real? Pues bien, si el simulacro de realidad es un elemento que compone (en parte) un imaginario colectivo, lo cual conlleva a opiniones, reflexiones e interpretaciones con un margen de colectividad, entonces se conformaría como realidad, pues finalizaría en una práctica social llegando a una categoría de fenómeno social, y todos los fenómenos sociales son reales.

Por otro lado, es necesario establecer como relacionamos los paradigmas explicativos y comprensivos en este texto. La utopía metodológica de muchos investigadores sociales es lo que nos ha legado P. Ricoeur (1995) en una dialéctica entre la explicación y comprensión. Pues en este caso, no es otro el fin (triangulación-complementación). El análisis sociofotográfico es frágil, sus cimientos están pendiendo de la rigurosidad y dinamismo del investigador, en lo que las dimensiones conjeturales de Ricoeur conforman un importante piso teórico. En esta explicación dialéctica, Ricoeur, nos otorga la posibilidad de interpretar una estable relación entre comprensión y explicación, y su aplicación a los fenómenos sociales, partiendo en nuestro caso, desde la base hipertextual de la fotografía. Esencialmente, tomaremos como primera intención la conjetura de, tal como nos decía el estructuralismo, el todo y las partes, para consecutivamente abordar su contextualización. Finalmente, los sentidos (conjeturales) del hipertexto fotográfico, será relativos a la contextualización semánticohistorica de los sujetos quienes interpretan, estas a su vez, inevitablemente vinculadas a las formas simbólicas pensadas a través de un sistema de lenguaje determinado. De esta forma, la descripción explicita de las conjeturas (su comprensión) nos otorgará una explicación científica. Claramente, la explicación aquí mencionada refiere a los principios semióticos y hermenéuticos planteados por Ricoeur, alejándose, por cierto, de la explicación de las ciencias naturales. Pues, he de considerar a la antropología una ciencia mediada (social y humana), que no escatima esfuerzos en desplazarse caprichosamente entre métodos, teoría e ideologías. Sin embargo, considerando la matriz y la esencia de la fotografía social, una concepción de Verwindug, en conceptos de Vattimo (1986), sería el phatos que construya un campo abierto y científico para la exploración humana, desuniversalizando o destotalizando la disciplina y abriendo los pasadizos del conocimiento.

\section{La muerte, inagotable fuente de investigación}

En la fotografía, pensar la muerte, que más bien es pensar la finitud, no solo se da tanto contraexistencia del ego, o del sujeto en una necesaria alteridad, una paradójica interpretación sería una "ontología del no ser". Este concepto, en sí mismo metafísico, constituye la cuestión filosófica y teológica que ha trascendido a través de la historicidad, y pues, no es algo poco relevante en la fotografía. No es en vano que Barthes construya prácticamente una tanatología de la fotografía en su texto La chambre claire, o La cámara lúcida (2009). 
Pues, si para Schopenhauer (2005) la muerte es algo consciente, tanto su existencia es pensada, y por lo tanto vivida, en algún sentido para la fotografía se constituye un elemento trascendental.

En el texto Cámara Lúcida de Barthes, notamos cierta fascinación por la fotografía como transporte de la muerte, pues, es un tema trascendental en cualquier análisis de la existencia. En efecto, la muerte no es la antítesis de la vida, sino que se transforma en una inherencia en la construcción del concepto propiamente tal, una dualidad. Basta recordar la ontología heideggeriana, donde el Dasein (ser-ahí), no es solo la existencia del Ser en el ente y el Ser en el mundo, lo cual lo constituye como Ser, sino que sin la muerte no sería Ser, a esto, Lévinas (1994) diría que el Dasein realmente muere en la medida en que este existe. De igual forma, en el nihilismo nietzscheano la muerte de Dios no significa la muerte de un Ser, sino, la muerte de un relato, de un discurso de la modernidad, provocando un proceso de transvaloración entre el todo (occidental) y la nada, entre la constitución valórica del ser y el vacío, la posibilidad de un superhombre no anclado a un sistema valórico histórico. Pues desde esta perspectiva, la muerte constituye una meganarrativa histórica por excelencia.

Estudiar la muerte, desde la antropología, no significa intentar obstinadamente encontrar un saber científico-social sobre que hay más allá de la vida, sino estudiar los procesos relativos a la materialización y representación de fenómenos sociales relacionados a ella, por cuanto constituye un concepto evidentemente polisémico. No es una búsqueda metafísica como respuesta explicativa, sino una comprensión metafísica-social que explique los hechos. Desde este punto de vista, la muerte no solo se manifiesta ritualmente en la sociedad, sino que a través del pensamiento, la interpretación y la representación (en nuestro caso fotográfica) podemos encontrar huellas que nos otorguen conjeturas sobre qué es socioculturalmente la muerte.

Como manifestó Evans-Pritchard (1973), la muerte ha permanecido de distintas formas en el pensamiento del hombre. Siendo un principio universal ineludible. Por otro lado, la incomprensión social de la muerte condujo a evolucionistas ha decir que esta es un proceso más sobrenatural que real (Taylor, 1981), desdeñando las dimensiones sociales y adjudicándole características metafísicas. Así, para el funcionalismo, esta tendría una función de roles, satisfacción de necesidades básicas, normas, parentesco, organización política, etc. Malinowski (1926); Evans-Pritchard (1940), entre otros. No obstante, Leví-Strauss (1988), desde el estructuralismo, afirmaría que la muerte no solo es un fenómeno simplemente natural y de características metafísicas y socio-estructurales (Dioses, status, roles, etc.), sino que es un proceso que se suscita tanto de forma ritual-práctica, como de forma filosófica, pues a través del pensamiento de la muerte las culturas se desenvuelven en una diversidad de significaciones que inciden en sus propias prácticas sociales y su propia constitución. C. Geertz (1992), relacionaría este fenómeno a las formas simbólicas, pues la muerte sería el reflejo de lo que las personas valoran y temen, por lo tanto, para la antropología constituye una vía en la búsqueda de la significación de la cultura. Esto por nombrar solo algunos.

La muerte es un nudo gordiano de incertidumbre, por lo que las opciones de la antropología navegan por los nubosos sentidos humanos. La muerte y su relación con el recuerdo no conforman en sí mismo elementos dispersos, sino que son inherentes. Conceptos como memoria y olvido-vida y muerte se simbolizan en todo lugar (Augé, 1998). Por otro lado, en antropología existe la denominada muerte social, que exime de toda prioridad la finitud orgánica. Esta muerte puede suscitarse en tanto separación experiencial de algún sujeto de un grupo social y toda aquella actividad que implique una relación directa o indirecta con la disolución de algún lazo experiencial o sensacional concreto de individuos, se manifiesta a través de un "hecho social", en tanto prácticas sociales sustentan estos procesos. Aquí, la muerte, conforme a su amplitud conceptual, nos conduce a interpretaciones sobre la trascendencia existencial de las personas, al olvido, aquellas que "viven" la muerte de una manera polidimensional, es la verdadera esencia de la muerte, el pensamiento de la ausencia y su 
manifestación sociocultural. Pues: "Todo hombre muere varias veces, y cada vez de una manera diferente: varias veces, puesto que muere tan a menudo como desaparecen, unos a otros, los vivos que se acordaban de él, y de una muerte diferente según la calidad y profundidad de la comunicación interrumpida" (Savater, 1995:148-149).

\section{La sociofotografía, entre los senderos de la ciencia y la filosofía}

Qué es la fotografía social entonces, sino una mezcolanza de conceptos y retóricas que conforman una tríada entre el lenguaje, socialización y pensamiento. Por un lado tenemos interpretación-comprensión (hermenéutica), por otro, tenemos la construcción de conocimiento (gnoseología-epistemología), y más profundamente, tenemos el análisis del Ser (ontología), como también, el lenguaje y la razón (lógica). De este modo, es indubitable la importancia que merece el estudio de la fotografía, y es necesario sobrepasar la banalidad que subsume a esta disciplina en una sociedad materializada y pragmática. Estudiar la fotografía social requiere la capacidad de comprender, cuestionar e interpretar a una sociedad en constante movimiento, en constante cambio. Es estudiarla desde su propio reflejo. La sociofotografía debe tener una orientación socioantropológica y sociosemiótica, desde la teoría y la metodología, al considerarse como una manifestación propia de la condición humana, desdeñarla es no comprender sus posibilidades, sus hechos y su historia. Abordarla así, conduciría a un estudio de versatilidades, de transmutaciones disciplinarias que involucraría un amplio aporte al conocimiento en esta área, y conformaría un constante proceso de construcción racional que tendría como finalidad ontológica un principio de reconocimiento del Yo en relación al Otro.

Verlo de esta manera, nos permitiría poder intentar analizar la fotografía y los hechos sociales no solo desde un paradigma de la explicación, sino también de la comprensión, es el complemento de disciplinas que en su constitución holística nos ayudarían a enfrentar el estudio de la totalidad social.

Clara está la complicación de esta propuesta, pues es solo un comienzo crítico, donde la fotografía intenta introducirse en medio de la batalla intelectual que emerge por la rivalidad de las ciencias; métodos positivos de las ciencias sociales o métodos hermenéuticos de las ciencias humanas, separados y unidos por metodologías instrumentales, pero carentes de una real articulación metodológica (científica, filosófica y social), que no omita el sentido común, que no generalice universalizando objetividades, que no se limite al empirismo para intentar comprender lo que en realidad representa la condición humana y que no caiga indiscriminadamente en el complejo enmarañado del subjetivismo. Todo un conjunto de manifestaciones que deben ser abordadas desde una óptica holística, como se pretende aquí adjudicar a las posibilidades cooperativas de una sociofotografía en la investigación social.

Entonces, ¿qué constituye a la fotografía, sino una multiplicidad de códigos, a priori, amorfos construidos por una reflexión individual que adquieren uno o muchos sentidos a través del spectator, relacionado a las condiciones de conocimiento adquirido de acuerdo a contexto, época y grupo sociocultural? Eso es, pues cuando hablamos de la fotografía como representación de la realidad, en absoluto nos referimos solo a una realidad empírica, sino a la realidad desde su más amplio espectro conceptual, en definitiva, hechos y pensamientos. Pues, podemos concluir a final de cuentas, que la fotografía y su interpretación no son dos cosas separadas.

\section{Bibliografía}

Augé, Marc. Las Formas del Olvido. Barcelona: Gedisa, 1998.

Barthes, Roland. La cámara lúcida. Barcelona: Paidós, 2009.

Baudrillard, Jean. Cultura y simulacro: la precesión de los simulacros. Barcelona: Kairós, 1998. 
Bourdieu, Pierre. Un arte medio: ensayo sobre los usos sociales de la fotografía. Barcelona: Gustavo Gili, 2003.

--. El sentido práctico. Madrid: Siglo XXI, 2008.

Cassirer, Ernest \& Imaz, Eugenio. Antropología filosófica: introducción .. a una filosofía de la cultura. México: Fondo de Cultura Económica, 1963.

Descartes, René. El discurso del método. Tres cantos: Akal, 2007.

Evans-Pritchard, E. E. Antropología social. Buenos Aires: Nueva Visión, 1973.

Foucault, Michel. Las palabras y las cosas: una arqueología de las ciencias humanas. Madrid: Siglo XXI, 1997.

--. La hermenéutica del sujeto: curso en el Collège de France, 1981-1982. México: Fondo de Cultura Económica, 2002.

Geertz, Clifford. La interpretación de las culturas. Barcelona: Gedisa, 1992.

Kant, Immanuel, y García Morente, Manuel. Crítica de la razón pura. Madrid: Tecnos, 2002.

Levinas, Emmanuel. Dios, la muerte y el tiempo. Madrid: Cátedra, 1994.

Lévi-Strauss, Claude. Antropología estructural. Barcelona: Paidós, 1987.

--. Tristes trópicos. Barcelona: Paidós, 1988.

Ricoeur, Paul. Teoría de la interpretación: discurso y excedente de sentido. Madrid: Siglo XXI, 1995.

Savater, Fernando. Invitación a la ética. Madrid: Planeta de Agostini, 1995, pp. 148-149.

Schopenhauer, Arthur, Díaz Fernández, Rafael y Chamorro Mielke, Joaquín. El mundo como voluntad y representación, Madrid: Akal, 2005.

Tylor, E. B., Suárez, Marcial y Radin, Paul. Cultura primitiva. Madrid: Ayuso, 1981.

Vattimo, Gianni. El Fin de la modernidad: nihilismo y hermenéutica en la cultura posmoderna. México, D.F.: Gedisa, 1986.

\section{3}

